\title{
A CATEGORIA GÊNERO NO GT HISTÓRIA DA EDUCAÇÃO DA ANPED: UM EXERCÍCIO DE CRÍTICA MARXISTA
}

André Luiz Sena Mariano

Romeu Adriano da Silva

\section{RESUMO}

O presente artigo busca problematizar a forma como a categoria gênero tem sido empregada na história da educação. Para tanto, foram levantados os trabalhos apresentados no GT História da Educação da ANPEd, que focalizavam as discussões sobre as relações de gênero. Em incursão nos dados, verificou-se a prevalência de um hiato entre os estudiosos da história e os da história da educação; além disso, constatou-se que os estudos, em sua grande maioria, fundamentam-se em paradigmas da nova história cultural, privilegiando a análise de aspectos pontuais em detrimento de explicações mais gerais. Este texto problematiza esse uso, advogando a importância e necessidade de que as explicações do fenômeno educacional em perspectiva histórica estejam balizadas na ciência da história e permitam, a partir disso, análises que levem em conta o fato dessas relações pertencerem a uma totalidade. Portanto, advoga o termo relações sociais de gênero, pois entende que, para além de disputa acerca do melhor termo a ser empregado, o que se propõe é que essas relações sejam vistas como históricas e sociais e, mormente, inserida nos modos de produção.

Palavras-chave: relações de gênero - historiografia - materialismo histórico

\section{THE CATEGORY OF GENDER IN THE HISTORY OF EDUCATION WG OF ANPED: AN EXERCISE OF MARXIST CRITICAL}

\begin{abstract}
This article aims to discuss the way the category of "gender" has been used in the History of Education. To achieve this objective, the papers presented in the History of Education Working Group at ANPEd Annual Meetings (in the period between 2000 and 2010) were analyzed in order to check the number of articles dealing with questions related to gender. The analysis of the data showed that, regarding the theoretical framework adopted in these articles, there is a "theoretical gap" among the researchers in the fields of History and History of Education. Besides, it was found that most investigations are based on theories that come from the New Cultural History, which implies a focus on specific aspects and not on overall ones. This article questions the validity of such analyses, and suggests that, in order to get an accurate understanding and explanation of the educational phenomena in a historical perspective, the analyses should be based on theories from the Science of History. It is supposed that the researchers should take into consideration that the educational phenomena are part of a totality. Therefore, the article pleads the term "social relations of gender", considering that, apart from terminological controversies, the analyses of gender related problems should be based on the assumption that they are historically and socially contextualized, and have a close connection with the production method prevailing in each society.
\end{abstract}

Keywords: Gender Relations; Historiography; Historical Materialism. 
A categoria gênero vem despertando grande interesse e ganhando evidente destaque na agenda da pesquisa educacional. Via de regra e em que pesem as divergências epistemológicas de algumas abordagens, conceitos como identidade e diferença, mormente sob a ótica daquilo que tem se convencionado denominar de pós-modernismo, destacam-se frente aos demais para a explicação do tema em tela. Tem-se assistido a uma postura de se recorrer a um arrazoado de conceitos que procuram atuar nas tais fronteiras do hibridismo, da fluidez, da assunção e negociação de múltiplas identidades; há forte apelo para que a diferença seja a categoria nevrálgica para explicar o gênero.

A partir dessa hipótese de trabalho - de que o gênero configura-se como um tema investigado sob a égide de perspectivas pós-modernas - que este trabalho propõe-se a analisar de que forma essa categoria vem sendo manipulada no campo da História da Educação. Para tanto, colocam-se alguns questionamentos tais como: é possível falar em predomínio das tendências pós-modernas nos estudos sobre gênero no campo da História da Educação? Se sim, quais desdobramentos podem ser identificados na manipulação que é feita da categoria? Tentando caminhar na contramão das ditas "novas tendências", é possível analisar o tema gênero em uma perspectiva de totalidade? $O$ que teria $o$ materialismo histórico a contribuir com o tema?

Dessa forma, o texto organiza-se em três sessões. Na primeira delas, apresentamos alguns elementos do embate posto entre o novo e o velho na pesquisa em História da Educação; a seguir, são apresentados os dados encontrados nos estudos selecionados estudos apresentados nas reuniões anuais da ANPEd, no GT História da Educação, entre os anos de 2000 e 2010; na terceira sessão, apresentamos as críticas historiográficas feitas a partir de elementos do materialismo histórico que permitem advogar a análise do tema em tela a partir da ciência una da história.

\section{GÊNERO: O NOVO E O VELHO EM DEBATE}

O breve panorama que fora apresentado anteriormente coloca como imperativo o reconhecimento de que a configuração do campo científico - retomando Bourdieu (2007) e sua afirmação acerca dos inúmeros fatores que o configuram - parece apontar para um predomínio de tendências pós-modernas (considerando a imprecisão teórico-metodológica que carregam, o que é típico de movimentos que empunham determinadas bandeiras) e de conceitos que apelam para uma abordagem preponderantemente subjetivista e com uma forte tendência a colocar acento no particular e no efêmero, quando não em procedimentos que não passam de descrição fenomênica desarticulada de interpretações de ordem estrutural e de totalidade do real. Tal abordagem parece converter-se em uma opção metodológica inexorável para o tratamento do gênero nas mais variadas áreas do conhecimento que constituem o campo educacional, indo das chamadas áreas práticas e perpassando os fundamentos da educação.

Em consonância com essa dispersão e pulverização teórico-metodológica, o gênero parece prescindir de uma abordagem histórica, uma abordagem da ciência da história, que busque compreender tal tema para além de uma história de múltiplas identidades (conforme sugere HOBSBAWN, 2011) e para além de um tema da moda, tema que configura a nova historiografia educacional brasileira (LOMBARDI, 2000).

No que tange a isso, Lombardi (1993) pondera que o tema gênero parece fazer parte do novo, de um novo que descarta o velho, mormente quando se reconhece o caráter obsoleto de seus potenciais explicativos do real. A respeito desse embate entre o novo e o velho, o autor assim se pronuncia: 
De forma geral, a argumentação em prol de 'novos objetos', de 'novos problemas', de 'novos métodos' e de 'novas fontes' para a pesquisa histórico-educacional brasileira, é tributária do entendimento de que a crise dos paradigmas das Ciências Humanas e Sociais delimita o colapso de um modelo de análise baseado numa perspectiva de caráter macroscópico, privilegiador das regularidades sociais, tendo por base uma lógica vinculada à tradição da modernidade, de fé na razão - enfim, um tipo de 'pensamento racionalista e determinista' há muito ultrapassado e em crise insuperável. (LOMBARDI, 1993, p. 27-8)

Apoiando-se em Marx, Lombardi (1993) é incisivo ao precisar as categorias como expressões de relações reais, o que nos alerta para o fato de que o esforço do cientista (em nosso caso mais precisamente o historiador que toma como objeto de investigação o fenômeno educacional) reside justamente no empenho em manejar as categorias de modo que estas não sejam alçadas à condição de autônomas em relação à totalidade de relações sociais próprias de uma formação social historicamente determinada. Nesse sentido, preocupados com a aparente negligência que tem sido dada ao tema gênero e à forma como esta categoria tem sido empregada em muitos estudos de história da educação - ainda que isso, por ora, se apresente como hipótese - procuramos neste trabalho erigir, por meio de uma pesquisa de levantamento bibliográfico, uma compreensão sobre as formas como o gênero tem sido abordado no campo da história, especificamente na história da educação. Conforme fora pontuado anteriormente, a temática perpassa diferentes áreas de conhecimento, podendo ser encontrada em distintos grupos de trabalho. Todavia, o propósito é compreender a abordagem da temática no campo da história da educação.

E por que eleger o GT História da Educação como foco? Porque, entre outros aspectos, a temática do gênero parece ter papel decisivo na configuração da produção do grupo. Como reforço ao argumento, vale mencionar a observação de Sanfelice (2012), que afirma haver três orientações na produção do GT, dentre as quais as relações de gênero apresentam-se como a segunda orientação, marcada pela influência dos trabalhos de Guacira Lopes Louro.

Conforme já fora apontado no início, trata-se de uma tentativa de analisar a manipulação da categoria gênero na História da Educação. Com isso, advogamos a importância de se reconhecer, na contramão das tendências postas na área, que o materialismo histórico, sobretudo se assumirmos a necessidade de ter o real, a prática dos homens, como foco de análise - tomando-os também o ponto de partida da análise configura-se como uma importante ferramenta. Isso porque, a partir de nosso ponto de vista, é imprescindível a abordagem da temática a partir da ciência da história, ciência una na forma como a concebiam Marx e Engels:

Nós conhecemos uma única ciência, a ciência da história. A história pode ser contemplada de dois lados, divida na história da natureza e na história dos homens. Os dois lados não podem ser divididos; enquanto existirem homens, a história da natureza e a história dos homens se condicionam mutuamente. (MARX; ENGELS, 2007, p. 39)

Destarte, procuramos advogar que se compreenda a categoria gênero como inserida no modo de produção capitalista, profundamente articulada e imbricada à discussão e compreensão da dinâmica das lutas de classes. Ao defender tal perspectiva, que leve a uma apreensão necessariamente histórica do objeto, defende-se que é preciso não falar somente em gênero, mas em relações sociais de gênero articuladas contraditoriamente com todo o 
conjunto de relações sociais existentes na sociedade concreta em que estas existem, numa perspectiva de totalidade.

Visamos, com essa perspectiva, perseguir os objetivos da necessária reconstrução da "frente da razão", de que nos fala Hobsbawm, razão essa ainda ameaçada pela historiografia atual, direcionada ao fragmento, ao efêmero, que abre mão da operação histórica de explicar, acabando por se constituir num verdadeiro "perigo político":

O grande perigo político imediato que ameaça a historiografia atual é o "antiuniversalismo": "minha verdade é tão válida quanto a sua, independente dos fatos". Esse antiuniversalismo seduz naturalmente a história dos grupos identitários em suas diferentes formas, para a qual o objeto essencial da história não é o que ocorreu, mas como isso que ocorreu afeta os membros de um grupo em particular. De modo geral, o que conta para esse tipo de história não é a explicação racional, mas a "significação"; não o que ocorreu, mas como sentem o que ocorreu os membros de uma coletividade que se define por oposição às demais em termos de religião, de etnia, de nação, de sexo, de modo de vida, ou de outras características. O relativismo exerce atração sobre a história dos grupos identitários. Por diferentes razões, a invenção massiva de contraverdades históricas e de mitos, outras tantas tergiversações ditadas pela emoção, alcançou uma verdadeira época de ouro nos últimos trinta anos. Alguns desses mitos representam um perigo público - em países como a Índia durante o governo hinduísta, nos Estados Unidos e na Itália de Silvio Berlusconi, para não mencionar muitos outros dos novos nacionalismos, acompanhados ou não de manifestações de integrismo religioso (HOBSBAWM, 2008, p.1).

Antes de iniciar as análises, faz-se mister salientar que, devido aos imperativos postos pela extensão e natureza de um trabalho desse tipo, não intentamos, em momento algum, esgotar as análises de todas as categorias, pois isso seria inviável em tão curto espaço. $\mathrm{O}$ que se procura é lançar elementos que permitam incitar um debate entre um pressuposto predominante na agenda das análises do tema (sobretudo, procurando apontar a manipulação da categoria em tela), com outro que reconhece a importância da Ciência da História para apreender o movimento do real, movimento determinante na compreensão dessa mesma categoria.

\section{O GÊNERO NO GT HISTÓRIA DA EDUCAÇÃO DA ANPEd}

Ao descrever o procedimento metodológico adotado neste trabalho, algumas observações de ordem geral configuram-se como condição sine qua non para evitar interpretações equivocadas. Em primeiro lugar e conforme salientamos outrora, trata-se de uma pesquisa de levantamento bibliográfico e não de pesquisa "estado da arte". Não foi foco esgotar determinada produção sobre uma temática em todas as fontes possíveis. $\mathrm{O}$ propósito foi o de compreender a forma como a categoria gênero tem sido utilizada no campo da História da Educação, sobretudo, considerando a envergadura do GT História da Educação da ANPEd para a própria organização e definição da área, como locus importante de debate e reflexões dos pesquisadores que em torno dele se aglutinam.

Um segundo esclarecimento é sobre a opção teórico-metodológica adotada. Talvez, caminhar na contramão do fluxo aparentemente dominante no campo seja um exercício profícuo de instaurar o debate e apelar para o revigoramento de pressupostos que estão 
sendo considerados como ultrapassados e que, em função disso, pouco teriam a contribuir com o movimento do real que se instaura na contemporaneidade.

Com isso, afirma-se que não é o propósito do presente texto, exigir que os estudiosos da temática do gênero afiliem-se ao referencial aqui adotado. Trata-se, na oposição de tal dogmatismo, de tentar construir vieses possíveis que permitam resgatar a dimensão histórica e social do tema proposto, sobretudo, quando se desenha um quadro de análise que traz à baila o caráter plural, compósito, heterogêneo e multifacetado do tema. Mais preocupante que isso, é o crescente movimento de alçar o fenômeno à categoria de campo do conhecimento, uma vez que, como se tenta evidenciar neste texto, mesmo no interior do campo da História da Educação, parece haver uma tentativa contumaz de "libertar" os temas dos cânones acadêmicos, prescindindo - em função do tão proclamado fim da história - de uma necessária e iniludível postura de compreender o tema em tela a partir de uma perspectiva histórica, ou seja, estabelecer o entendimento de que as categorias só podem corresponder a relações concretas no interior de uma sociedade concreta, com todas as consequências que se pode tirar disso.

A partir desses apontamentos, é importante sinalizar que, um primeiro aspecto, refere-se ao foco dos textos levantados. Durante o procedimento de procura dos textos, percebeu-se que a temática gênero aparecia numa quantidade razoável de estudos. No entanto, o foco era angariar aqueles que apresentassem a temática como central em suas discussões e não como secundária. Isso levou a encontrar apenas 10 textos que abordaram o tema, em um período que comportou 11 reuniões anuais.

Numa incursão preliminar pelos dados levantados, é possível perceber que, a despeito do baixo número de textos selecionados, a temática da feminização do magistério foi a preponderante nos estudos; na sequência, a temática da escola normal (em muitos casos, imbricada à da feminização) também apareceu de maneira expressiva; por fim, encontrou-se estudo sobre o tema da masculinidade na literatura.

Outro aspecto que merece ser colocado em relevo é a diversificação das fontes. Para além das fontes historiográficas "tradicionais", há estudos que lidam com imagens, histórias de vida e fontes literárias.

Além de descrição e identificação das fontes, mostra-se imprescindível apresentar a forma como a categoria gênero tem sido manipulada pelos autores dos 10 textos selecionados. Com relação a isso, é possível afirmar que, longe de ser uma mera listagem de autores utilizados, as principais referências a partir das quais os estudos ancoram suas análises são a brasileira Guacira Lopes Louro, o português Antonio Nóvoa e a francesa Michelle Perrot. Longe de serem autores de extrema predominância nos estudos, eles são utilizados, em média, por 3 estudos. Além de Perrot, aparecem autores como Hobsbawn, Ginzburg, Dosse, Le Goff e Chartier. Não obstante essa lista revele uma pluralidade de orientações teórico-metodológicas, os autores são utilizados por, no máximo, 2 trabalhos o que parece sinalizar para um hiato entre os estudiosos da história da educação e os historiadores de ofício. Quando se constata uma aproximação dos estudiosos da temática na área de educação com os historiadores, esta se apresenta de forma tímida, embora entendamos que as pesquisas e estudos em história da educação não podem ser outra coisa além de pesquisas e estudos históricos, ou seja, falar em história da educação é considerar que partilhamos da compreensão de que o que se pretende é designar e precisar o objeto (fenômeno educativo) abordado na perspectiva da ciência da história.

Identifica-se, outrossim, uma tentativa de apresentar a feminização do magistério como articulada à discussão alusiva ao trabalho, mormente a partir do ingresso da mulher no mercado de trabalho via profissão docente. Percebe-se, ainda, uma tentativa, embora 
tímida, de articular o fenômeno da feminização do magistério com elementos de classe social ou com aspectos do que alguns trabalhos denominaram grupo social.

Em função de, a partir de pressuposto assumido por este trabalho, ficar quase indissociável apresentar os dados/características dos estudos sem que se erijam análises, na próxima seção iniciaremos o debate acerca da forma como a categoria gênero vem sendo apropriada pelos textos.

\section{GÊNERO, HISTÓRIA E EDUCAÇÃO: APONTAMENTOS PARA O DEBATE}

Conforme fora salientado no início deste texto, a reflexão aqui proposta procura caminhar na contramão de um posicionamento teórico que parece predominante no que se refere aos estudos relativos ao gênero nos diferentes campos do conhecimento. Seja na história, na sociologia, no currículo, o que se percebe é um movimento de configuração do campo científico (BOURDIEU, 2007) em que prevalecem os paradigmas com o prefixo "pós". Seja pós-estruturalismo ou pós-modernismo, percebe-se uma maneira subjetivista de lidar com o fenômeno.

Com isso, podemos retomar discussões tratadas por Saviani, em seu livro Escola e Democracia (2003), sobretudo aquelas em que o autor reporta-se à teoria da curvatura da vara proposta por Lênin.

A julgar pela forma como os trabalhos selecionados lidam com a categoria gênero com rara exceção - identifica-se uma prevalência da História Cultural ou daquilo que autores como Lombardi (2000) e Bittar (2012) vão chamar de "nova historiografia educacional". Para ambos os autores, essa forma de entender e lidar com os objetos, em primeiro lugar, os alça à categoria de campos científicos, por entendê-los como autônomos e capazes de produzir métodos explicativos por si mesmos. Em segundo lugar, a maneira como a categoria é trabalhada leva o leitor a inferir que a forma vigente no campo é a mais atual, aquela que melhor responde aos fenômenos da contemporaneidade, o que se verifica mormente na tentativa de desqualificar análises que tentem compreender a categoria gênero como inserida em relações sociais mais amplas.

No que se refere a isso, Lombardi (2000) afirma que as novas concepções de ciência e, como consequente, a "nova história da educação brasileira" parecem abrir três outras possibilidades quanto ao fazer científico do historiador. Dentre essas, o autor destaca e analisa um artigo de Guacira Lopes Louro, em que ela advoga a necessidade de se abrir a novas perspectivas de análise para que seja possível responder a novas perguntas sobre antigos temas. Ao fazer isso, Lombardi afirma que a autora considera, principalmente, a importância de se construir uma ótica para a história a partir dos vencidos, ou seja, vincular os estudos sobre gênero na história da educação aos estudos sobre história das mulheres.

Acrescentando elementos a esse embate entre o novo e o velho na história da educação, parece ser consensual que os estudos sobre as relações de gênero configuram-se como "novidade" e, por assim o ser, não podem ser analisados a partir de premissas do velho, pois o seu esgotamento mostra-se evidente com a crise instaurada nas Ciências Humanas e Sociais.

Todavia, neste estudo, defendemos a importância do chamado velho paradigma para a análise das relações de gênero em perspectiva histórica. Isso porque concordamos com Sanfelice (2000), quando afirma que:

[...] a) aderir ao 'novo', divulgar o 'novo', sem ter o domínio crítico epistemológico do 'velho' que estaria sendo superado pode ser descaso, 
ingenuidade ou mesmo intencionalmente a opção por outros interesses. É, sem dúvida, uma postura 'novidadeira'.

b) propor novos objetos, novos métodos, novas abordagens para a pesquisa historiográfica, sem disciplina, pode ser um simples aligeiramento, descuido metodológico ou teórico para com a construção da ciência da história. É óbvio, entretanto, que estas questões não se colocam para quem não quer fazer ciência ou mesmo duvida da possibilidade de fazê-lo. (SANFELICE, 2000, p. 40)

Com isso, ao reafirmamos a nossa afiliação ao "velho" - ao materialismo histórico defendemos que não é possível falar simplesmente em gênero, mas sim em relações sociais de gênero. Relações essas que são conformadas pelos modos de produção da vida humana e, por isso, obedecem aos rumos da história. Corroborando Lombardi ao citar Engels (2012), cada vez que se alteram os modos de produção, alteram-se os modos de compreender e analisar a materialidade a partir da qual se produz a vida humana.

Analisar a feminização do magistério como um fenômeno que não decorre dos modos de produção da vida - uma vez que o ingresso das mulheres no mercado de trabalho, via docência, poderia significar, entre outras coisas, uma emancipação social em relação à opressão masculina, leva a um tratamento equivocado da própria categoria classe social. Dessa forma, a utilização do termo relações sociais de gênero, longe de ser uma querela conceitual em torno da melhor expressão a ser utilizada nas pesquisas educacionais, é uma defesa contumaz de se reconhecer a existência de relações reais, concretas e históricas entre os homens, portanto, relações sociais.

Entre os estudos selecionados, parece haver o consenso de que a discussão sobre a feminização do magistério e a dinâmica de classes sociais se resolva com a simples afirmação de que as mulheres passaram a ter acesso ao mercado de trabalho e isso lhes permitiu participação ativa na produção da vida humana.

Mesmo confinada ao âmbito doméstico, será possível falar em uma mulher que não participa da produção da vida humana? Ao restringir a atuação feminina ao lar, pode-se afirmar, a julgar pelo que os trabalhos apontam em suas análises, que os modos de produção atingem exclusivamente a vida profissional, ficando, portanto, a vida doméstica alheia à dinâmica da história? Parece-nos haver, nesta forma de considerar as coisas, um certo reducionismo e um estreitamento da compreensão do que sejam os modos de produção, na medida em que estes não são tomados na real amplitude em que a vida humana se produz e reproduz.

Não se propõe neste texto, como alguns podem inferir, que a dinâmica de gênero seja mecanicamente determinada pelo econômico, que todas as formas das relações sociais e as instituições de uma sociedade sejam tomadas a partir de uma perspectiva determinista, pois isso seria incorrer no equívoco de engessamento das categorias de análise do real. E mais, seria desconsiderar, por exemplo, a crítica que Thompson dirige a Althusser por considerar que a forma como este lida com as categorias do materialismo histórico lhe retira a própria abordagem histórica e se restringe, portanto, a uma postura idealista de fazer ciência (THOMPSON, 1981). Trata-se, isso sim, de reconhecer que o real é "síntese de múltiplas determinações", como o demonstrou Marx (2003), e que essa síntese existe no interior de uma lógica inerente a um modo de produção, no interior de uma totalidade contraditória. Deste modo, é cabível considerar que, em se tratando do modo de produção capitalista, não podemos abrir mão - sob pena de perdermos a referência do real - de que há, necessariamente, a determinação do econômico em última instância, como o assevera Engels (s/d). 
Em contrapartida, também não se propõe curvar a vara ao lado oposto (não obstante reconheçamos seu caráter mais que profícuo para instaurar o debate), como o faz Haug, ao afirmar que "as relações de produção são de fato sempre relações de gênero" (HAUG, 2007, p.6).

De acordo com essa autora, é possível afirmar que:

[...] as relações de gênero são relações de produção. Isto invalida a tendência de pensar nelas puramente como relações entre homem e mulher. Pelo contrário, os diferentes modos de produção na história devem ser sempre estudados como moldados por relações de gênero, isto é, em termos de como a produção da vida é regulada na totalidade das relações de produção, e como sua relação com a produção dos meios de vida é organizada (HAUG, 2007, p. 9).

E autora ainda acrescenta: "sustento que todas as práticas na sociedade estão determinadas por relações de gênero - têm um subtexto de gênero - são, por isso, colocadas em chave de dominação e que, portanto, devemos incluí-las em qualquer análise e compreensão da sociedade" (HAUG, 2007, p.10).

Embora reconheçamos, como já fora apontado, que o movimento de curvar a vara seja salutar e, por vezes, necessário para o avanço do conhecimento científico, não é o propósito deste texto. Não obstante se verifique no trabalho da autora uma tentativa de erigir elementos para uma análise das relações de gênero a partir do materialismo histórico, destacando a categoria modo de produção como fulcral para a análise da vida real, o que se percebe é um engessamento idealista da realidade.

Ainda que possa não ter sido seu propósito, afirmar que as relações de gênero são componentes determinantes de "todas" as relações humanas é simplesmente ignorar a dinâmica contraditória presente na sociedade capitalista. Há que se considerar que entre os termos "componentes" e "determinantes" existe uma diferença notória, cuja consequência pode ser a construção de análises imprecisas. As relações de gênero são, evidentemente, "componentes" das relações humanas, mas não orientam e determinam o fio condutor do desenvolvimento dessas relações, antes, parece-nos que são moldadas e vão ganhando formas variáveis historicamente. Não é possível assinalar que uma categoria social é sempre o vetor de explicação da vida social. Com isso, afirmamos o cuidado necessário para qualquer análise do real que se ancore sob a égide do materialismo histórico, ou seja, se, conforme afirma Engels, ao corrigir interpretações equivocadas dos escritos marxianos, em nenhum momento o fator econômico foi apontado como o único determinante da sociedade, o mesmo vale para as relações de gênero.

A curvatura da vara, embora sugestiva, nos leva a discordar de Haug (2007). As relações de gênero compõem, a partir de nosso ponto de vista, uma das muitas dinâmicas da vida social, uma instância em que podem ser verificadas as relações de opressão, dominação e resistência. As relações de gênero, assim como as determinações econômicas, sempre precisam ser vistas, concebidas, analisadas a partir da totalidade histórica das relações sociais.

Com isso, afirmamos que seria mais preciso entender que nas relações de produção estão inseridas e, é claro, delas são inelimináveis, as relações de gênero, ou seja, importa considerar, como Marx, que o concreto sempre é síntese de múltiplas determinações. Procura-se, sim, retomar as afirmações de Engels, em uma de suas cartas, quando argumenta que nem ele nem Marx propuseram que o critério econômico seja o único determinante da vida humana. A esse respeito, Engels afirma que 
[...] Segundo a concepção materialista da história, o fator que, em última instância, determina a história é a produção e a reprodução da vida real. Nem Marx nem eu afirmamos, uma vez sequer, mais do que isso. Se alguém o modifica, afirmando que o fato econômico é o único fato determinante, converte aquela tese numa frase vazia, abstrata e absurda. A situação econômica é a base, mas os diferentes fatores da superestrutura que se levanta sôbre ela - as formas políticas da luta de classes e seus resultados, as constituições que, uma vez vencida uma batalha, a classe triunfante redige, etc, as formas jurídicas, e inclusive os reflexos de tôdas essas lutas reais no cérebro dos que nelas participam, as teorias políticas, jurídicas, filosóficas, as idéias religiosas e o desenvolvimento ulterior que as leva a converter-se num sistema de dogmas - também exercem sua influência sôbre o curso das lutas históricas e, em muitos casos, determinam sua forma, como fator predominante. Trata-se de um jôgo recíproco de ações e reações entre todos êsses fatores... (ENGELS, s/d, p. 284).

Isso significa que, se quisermos entender a dinâmica da vida social, principalmente, considerando o papel nevrálgico dos modos de produção sobre a vida humana, não se deve falar em gênero somente, pois isso é exercício diletante, escolástico e de compreensão do mundo como fruto de práticas discursivas, portanto, passível de permitir novas histórias, releituras de fenômenos sociais a partir da subjetividade de cada pesquisador (afinal, para Foucault, grosso modo, é possível dizer que existem tantas leituras e, portanto, releituras, quantos sujeitos existirem). É preciso entender o tema em tela a partir das relações sociais, ou seja, o que existe, na vida social, não é gênero per si, mas sim relações sociais de gênero.

A riqueza das observações de Engels está em encaminhar o entendimento de que o que determina a história e a forma como os homens produzem e reproduzem a sua vida, e esta "vida" não é redutível ao que se planta para comer ou às formas das trocas de riquezas para atender às necessidades mais básicas dos indivíduos, mas sim que esta "vida" é o conjunto de todas as atividades práticas dos homens, aí inseridas suas relações de gênero, a educação das crianças, a produção do conhecimento científico etc. Importa, é claro, entendermos que o econômico é o determinante em última instância, pois não se pode perder de vista a referência ao real, ou seja, ao fato de que os seres humanos, para continuarem a existir, precisam estar vivos, pois, como asseveram Marx e Engels: "O primeiro pressuposto de toda a história humana é, naturalmente, a existência de indivíduos humanos vivos." (MARX; ENGELS, 2007, p. 41)

Ao compreendermos os gêneros a partir das relações sociais, supera-se uma abordagem discursiva, uma vez que se coloca como imperiosa a compreensão de como os homens se fazem homens e de como as mulheres se fazem mulheres em relações sociais. As relações sociais de gênero fazem parte das muitas relações existentes no mundo material e, portanto, configuram-se como um dos muitos fatores (tal qual afirmam Marx e Engels) que determinam as forças sociais capazes de alterar os modos de produção. Ainda como advogam os pensadores, não se trata de reduzir as relações sociais de gênero à dinâmica econômica; trata-se, sim, de reconhecer que há múltiplos fatores que condicionam a vida humana e, em última instância, o econômico é o fator determinante.

Outro aspecto que chama a atenção pela fragilidade é a pouca recorrência que os estudiosos da História da Educação fazem aos historiadores em geral. Nesse sentido, mesmo decorridas algumas décadas da publicação de seu texto, Mirian Warde (1990) continua tendo razão em seu argumento: ao menos os historiadores se aludem. 
Nesse assunto, Bittar aponta as fragilidades e distanciamentos que são verificados entre os historiadores e os historiadores da educação. Para ela, isso parece ser corolário da hegemonia da História Cultural. De acordo com ela, essa tendência nos estudos sobre a história da educação brasileira leva os pesquisadores a inferir e a defender o pressuposto de que a compreensão de um objeto particular - no nosso caso, as relações de gênero - não deve estar conectada a uma explicação mais abrangente. Acerca dessa ponderação, afirma a autora:

Os resultados tem sido estudos sem alcance algum, sem capacidade explicativa, enquanto as obras de caráter mais geral passaram a ser rejeitadas pela produção universitária e, não raro, classificadas como ultrapassadas. A esse respeito, em recente entrevista na qual avalia o efeito dessa influência na produção historiográfica brasileira, Laura de Mello e Souza considera como grave erro a perda das histórias gerais, constatando que a última elaborada entre nós foi a História geral da civilização brasileira, organizada por Sérgio Buarque de Holanda, enquanto em alguns países essa tradição ainda se mantém. (BITTAR, 2012, p. 100-1, grifo nosso)

O que se percebe, além da fragilidade exposta pela autora, é a prática de um exercício escolástico, amiúde, preocupado com discursos e com formas de abordar a temática de gênero como fruto da linguagem. Em outras palavras, parece que o problema real das relações de gênero reside no simples fato de, durante o processo de escrita de um texto ou de fala de um palestrante, abordar aos presentes com cumprimentos tanto no masculino quanto no feminino. Ora, de que resolve alterar discursos se a prática, a vida real, continua obedecendo aos mesmos padrões sociais? Será que tratar professoras e professores diferenciadamente, dando ênfase ao microscópico e à efemeridade das práticas discursivas, altera as condições concretas de opressão e desigualdade? Qual potencial os discursos possuem para alterar os modos de produção?

No que se refere a isso, é importante recorrer a Eric Hobsbawm, principalmente quando o eminente historiador explicita sua preocupação com os usos e abusos que estão sendo feitos da História nos mais variados âmbitos. Hobsbawm manifesta sua preocupação com o fato de que, para ele, os historiadores estão prescindindo da distinção entre fato comprovável e ficção. Em suas palavras:

\footnotetext{
Nas últimas décadas, tornou-se moda, principalmente entre pessoas que se julgam de esquerda, negar que a realidade objetiva seja acessível, uma vez que o que chamamos de 'fato' apenas existem como uma função de conceitos e problemas prévios formulados em termos dos mesmos. O fato que estudamos é só um constructo de nossas mentes (HOBSBAWM, 2011, p. 8).
}

Parece predominar o subjetivismo, a construção de uma realidade a partir de novas leituras, de reinventar a história das relações de gênero negando a objetividade da realidade concreta e, como corolário disso, a determinação que os modos de produção exercem na organização dessas relações.

Embora não seja um aspecto encontrado em todos os textos (portanto, não incorreremos no equívoco de estabelecer generalizações para o conjunto analisado), verifica-se que uma representação significativa deles afirma que é necessário fazer novas perguntas aos velhos problemas e, ao fazer isso, permitir a criação de novos passados. 
A partir disso é possível inferir que a própria história está sendo sacrificada, pois, se a qualquer tempo podemos fazer novas perguntas e criarmos os passados que subjetivamente quisermos criar, então, precisaremos assumir que as relações de gênero nunca estiveram presentes na história da humanidade. Por que é necessário, ao abordar as relações sociais de gênero, criar novos passados? Elas nunca existiram no plano concreto das relações entre os homens?

$\mathrm{O}$ embate entre o novo e o velho na historiografia educacional brasileira, que permite um descarte frágil, apressado e banal de qualquer referencial considerado obsoleto - leia-se aqueles que procuram estabelecer leituras e análises de tendências mais gerais da sociedade - nos faz diagnosticar a fragilidade do pensamento pedagógico que se produz no Brasil, mormente quando se percebe uma tentativa inócua de se criar um zero histórico. Com isso, assistimos ao crescente arrazoado de afirmações que desqualificam o velho e que o acusam de anacronismo, ainda que seu objeto de análise seja sempre as relações reais que homens e mulheres estabelecem entre si, reconhecendo que tais relações se dão imersas em contradições próprias do capitalismo.

\section{CONSIDERAÇÕES FINAIS}

Longe de esgotar o potencial dessas discussões, o propósito é levantar o debate e trazer à baila elementos que parecem ter sido ignorados pela pesquisa educacional. Para tanto, ao continuarmos no debate entre o velho e novo, outra questão se coloca como imperiosa para a crítica aqui empreendida. Nesse sentido, recorremos a uma importante historiadora do tema das mulheres, pois, a nosso ver, parece que sua proposição está sendo mal interpretada. A francesa Michelle Perrot, ao discutir a mulher popular rebelde, afirma que:

As mulheres não são passivas nem submissas. A miséria, a opressão, a dominação, por reais que sejam, não bastam para contar a sua história. Elas estão presentes aqui e além. Elas são diferentes. Elas se afirmam por outras palavras, outros gestos. $\mathrm{Na}$ cidade, na própria fábrica, elas têm outras práticas cotidianas, formas concretas de resistência - à hierarquia, à disciplina - que derrotam a racionalidade do poder, enxertadas sobre seu uso próprio do tempo e do espaço. Elas traçam um caminho que é preciso reencontrar. Uma história outra. Uma outra história. (PERROT, 2010, p. 212)

Fica evidente o quanto Michelle Perrot não nega a materialidade dos fatos, especialmente quando afirma que a miséria, a opressão e a dominação são reais. Agora, quando a autora encerra propondo uma outra história, não se pode inferir que ela esteja suscitando a construção de novos passados para as mulheres, pois seria contrapor-se ao que ela mesma reconhece no início de seu excerto. O que se pode depreender é que a autora proclama por uma história que não tenha as mulheres como submissas, passivas e, portanto, como seres que estão, inexoravelmente, imersos em relações de opressão, pois tal postura sustenta-se em concepções apriorísticas do que sejam as relações de gênero, independentes do que a investigação histórica possa nos revelar.

Perrot procura mostrar, ao longo de uma de suas obras, o papel contraditório que a mulher exerce na sociedade, estando longe de ser classificada como um ser com atitudes lineares. Se a mulher está imersa em uma sociedade contraditória, é fato que suas relações 
sociais, bem como a sua atuação, não se fazem soltas no espaço e sem as contradições que determinam o seu tempo. Não se trata, portanto, de reinventar outras histórias - a história de identidades que Hobsbawm (2011) critica - mas trata-se, sim, de localizar a mulher no tempo e no espaço históricos e reconhecer que as relações sociais de gênero são tão contraditórias quanto às sociedades aonde elas ocorrem. E mais: trata-se de reconhecer que homens e mulheres se fazem sujeitos históricos em meio e por essas contradições.

Mulheres e homens ou qualquer outra categoria social de pessoas existem em condições historicamente determinadas, e existem como pessoas ativas no interior dessas mesmas condições históricas determinadas. Entendemos que sua atividade prática, que a práxis, portanto, entra aqui como o fundamental critério de verdade para que possamos conhecer em maior profundidade e clareza as relações de gênero havidas, construídas social e historicamente.

É a partir desse pressuposto - o de considerar a ação humana em condições que os homens não podem escolher, como critério de verdade - que defendemos, a partir das ideias expostas neste tex to o uso da expressão "relações sociais de gênero". Longe de erigir um debate escolástico acerca do termo que deve ser empregado na compreensão do fenômeno - um debate inócuo -, preocupamo-nos em procurar contribuir para que as relações concretas havidas na história entre homens e mulheres - e vale sempre lembrar, ou qualquer outra categoria social - não sejam menosprezadas, relegadas a segundo plano. Preocupados com o sacrifício que parece se construir em torno da história, apelamos para uma análise das relações materiais, para uma investigação que apreenda a verdade da história não como produto do discurso ou de mentes humanas, tal como numa postura idealista e subjetivista, que permite ao investigador não só recriar uma realidade ou um passado, mas também lhe permite criar, fundar, a própria realidade como produto do seu pensamento. Se as relações de gênero são complexas, e concordamos que sejam, entendemos, contudo que essa complexidade não impede a lógica, não impede a explicação histórica numa perspectiva de totalidade, como o assevera Pierre Vilar:

Afinal, quer se trate de organismos biológicos e humanos ou de máquinas por nós mesmos fabricadas, a complexidade não impede a lógica, e é a lógica que é preciso estabelecer ou estudar. [...] No entanto, a tendência - de resto, em todas as ciências - é de especialização, e no domínio social vemos estabelecerem-se, de um lado, economistas, de outro, etnólogos, sociólogos, psicólogos do individual e do coletivo, em suma, inúmeras especializações. Eu não creio que seja fácil chegar a sínteses num terreno como esse, mas não seria o historiador, justamente, o mais aparelhado para fazê-lo? (D'ALESSIO, 1998, p. 49)

Estamos cientes de que as análises aqui empreendidas não se esgotam na natureza deste trabalho (em função de sua extensão, por exemplo) e que não se configura como nosso objetivo exigir dos autores dos estudos selecionados a adesão à afiliação teórica aqui advogada. Nosso intento é, conforme sinalizamos anteriormente, caminhar na contramão daquilo que parece predominar no campo e instaurar o debate.

\section{Referências}

BITTAR, Marisa. A pesquisa em História da Educação no século XX: uma aproximação com o campo da História. In: BITTAR, Marisa et. al. (orgs.) Pesquisa em educação no Brasil: balanços e perspectivas. São Carlos - SP: EdUFSCar, 2012, p. 87-116. 
BOURDIEU, Pierre. O poder simbólico. 11 a ed. Rio de Janeiro: Bertrand Brasil, 2007.

D’ALESSIO, Márcia M. Reflexões sobre o saber histórico - entrevistas com Pierre Vilar, Michel Vovelle e Madeleine Rebérioux. São Paulo: Editora da Unesp, 1998.

ENGELS, Friedrich. "Carta a Joseph Bloch". In: MARX, Karl; ENGELS, Friedrich. Obras Escolhidas. São Paulo: Alfa-Omega, s/d. p. 284-286, v.3.

HAUG, Frigga. Para uma teoria das relações de gênero. IN: BORON, Atilio; AMADEO, Javier; GONZALES, Sabrina. A teoria marxista hoje: problemas e perspectivas. FLACSO, 2007, p. 1-14 (texto mimeografado).

HOBSBAWM, Eric. Sobre a história. 2a ed. São Paulo: Companhia das Letras, 2011.

HOBSBAWM, Eric. "O desafio da razão: manifesto para a renovação da história”. Disponível em www.cartamaior.com.br (2008)

LOMBARDI, José Claudinei. Marxismo e história da educação: algumas reflexões sobre a historiografia educacional brasileira recente. Tese de doutorado. Faculdade de Educação, Universidade Estadual de Campinas, 1993.

LOMBARDI, José Claudinei. "Historiografia educacional brasileira e os fundamentos teórico-metodológicos da história”. In: LOMBARDI, José Claudinei. (org.) Pesquisa em educação: história, filosofia e temas transversais. $2^{\mathrm{a}}$ ed. Campinas - SP: Autores Associados, 2000, p. 7-32.

LOMBARDI, José Claudinei. Embates marxistas: apontamentos sobre a crise pósmodernidade e a crise terminal do capitalismo. Campinas - SP: Navegando/Librum, 2012.

MARX, Karl. Contribuição à crítica da economia política. São Paulo: Martins Fontes, 2003.

MARX, Karl; ENGELS, Friedrich. A ideologia alemã. Rio de Janeiro: Civilização Brasileira 2007.

PERROT, Michelle. Os excluídos da história: operários, mulheres, prisioneiros. São Paulo: Paz e Terra, 2010.

SANFELICE, José Luis. A pesquisa histórico-educacional: impasses e desafios. IN: LOMBARDI, José Claudinei. (org.) Pesquisa em educação: história, filosofia e temas transversais. $2^{\text {a }}$ ed. Campinas - SP: Autores Associados, 2000, p. 33-42.

SANFELICE, José Luis. Apontamentos sobre a pesquisa em História da Educação no Brasil do século XX. In: BITTAR, Marisa et. al. (orgs.) Pesquisa em educação no Brasil: balanços e perspectivas. São Carlos - SP: EdUFSCar, 2012, p. 55-86.

SAVIANI, Dermeval. Escola e democracia. $36^{\mathrm{a}}$ ed. Campinas - SP: Autores Associados, 2003.

THOMPSON, Edward P. A miséria da teoria ou um planetário de erros: uma crítica ao pensamento de Althusser. Rio de Janeiro: Zahar Editores, 1981.

WARDE, Mirian J. Contribuições da história para a educação. Em aberto. Brasília - DF: 1990, p. 2-11. 